\title{
Quantitative determination of c-myc facilitates the assessment of prognosis of OSCC patients
}

\author{
M. PÉREZ-SAYÁNS ${ }^{1 *}$, J.M. SUÁREZ-PEÑARANDA ${ }^{2 *}$, E. PADÍN-IRUEGAS ${ }^{3}$, P. GAYOSO-DIZ ${ }^{4}$, \\ M. REIS-DE ALMEIDA ${ }^{1}$, F. BARROS-ANGUEIRA ${ }^{5}$, P. GÁNDARA-VILA ${ }^{1}$, \\ A. BLANCO-CARRIÓN ${ }^{1}$ and A. GARCÍA-GARCÍA ${ }^{1}$
}

\begin{abstract}
${ }^{1}$ Oral Medicine, Oral Surgery and Implantology Unit, Faculty of Medicine and Dentistry, Instituto de Investigación Sanitaria de Santiago (IDIS), Santiago de Compostela; ${ }^{2}$ Department of Pathology and Forensic Sciences, University Hospital and School of Medicine of Santiago de Compostela; ${ }^{3}$ Laboratorio Oncología Traslacional, Fundación Idichus, Hospital Clínico Universitario de Santiago de Compostela; ${ }^{4}$ Clinical Epidemiology and Biostatistics Unit, Hospital Clínico Universitario de Santiago de Compostela, Instituto de Investigación Sanitaria de Santiago (IDIS), Santiago de Compostela; ${ }^{5}$ Unidad de Medicina Molecular, Fundación Pública Galega de Medicina Xenómica, Edificio de Consultas Planta-2, Hospital Clinico Universitario, Santiago de Compostela, Spain
\end{abstract}

Received December 3, 2013; Accepted January 24, 2014

DOI: $10.3892 / o r .2014 .3040$

\begin{abstract}
Myc genes are a family of proto-oncogenes whose proteins are implicated in the regulation of cell proliferation, differentiation and apoptosis, and in regulating the activity of genes involved in cell division. The aim of the present study was to establish a quantitative description of the expression of c-myc and evaluate its relationship with other clinical and prognostic factors, as well as to establish a multivariate survival prediction model. This is a retrospective study of 68 patients diagnosed with oral squamous cell carcinoma (OSCC). We constructed a tissue microarray for investigating the expression of c-myc by immunohistochemistry. Statistical analyses were carried out, and a multivariate model that predicts survival was established. The average expression of c-myc was 50.32 (SD, 26.05) with a range from 6.60 to 99.48; similar for initial and advanced tumor stages. Non-smoking patients had higher levels of c-myc, showing statistically significant differences (Kruskal-Wallis $\chi^{2}=5.975 ; \mathrm{P}=0.05$ ). We found no statistically significant relationship between the quantitative expression of c-myc and any other clinical or pathological parameters. For each unit of increase of c-myc, the risk increased by 1.15 $(\mathrm{P}<0.001$; HR, 1.150; 95\% CI, 1062-1245). Further study of this protein, which may have a significant diagnostic, prognostic
\end{abstract}

Correspondence to: Dr Mario Pérez-Sayáns, Oral Medicine, Oral Surgery and Implantology Unit, Faculty of Medicine and Dentistry, Instituto de Investigación Sanitaria de Santiago (IDIS), Entrerríos s/n, C.P. 15782, Santiago de Compostela, Spain

E-mail: perezsayans@gmail.com

*Contributed equally

Key words: c-myc, oral squamous cell carcinoma, multivariate model of survival and therapeutic value is warranted. Its determination can be valuable when used together with other markers to assess the prognosis of OSCC patients.

\section{Introduction}

An oral squamous cell carcinoma (OSCC) is a tumor characterized by multiple multistep genetic alterations, that lead to genomic instability and disordered cell growth due to oncogene overexpression, subexpression of tumor-suppressor genes and other genetic, epigenetic and microRNA alterations (1-5). The two most studied oncogenes (dominant) in human solid tumors are HER-2/neu and c-myc; while p53 is a tumor-suppressor gene involved in almost all human malignancies (6).

Myc genes are a family of proto-oncogenes comprised of several members (L-myc, N-myc and c-myc). Myc proteins are involved in the regulation of cell proliferation, differentiation and apoptosis, and in regulating the activity of genes involved in cell division (7). Contrary to classical theory, c-myc is also implicated in the control of apoptotic phenomena, possibly leading to tumor regression depending on cell type, cell interactions, extracellular matrix and neighboring cells $(3,8,9)$. The c-myc protein acts as a transcription factor (10), and ectopic expression of this protein is sufficient to induce the progression of the cell cycle. c-myc is also related to a poor tumor prognosis (11-14) as well as the self-renewal of tumor stem cells (15-18).

The aim of the present study was to establish a quantitative description of the expression of c-myc and to evaluate its relationship with clinical and prognostic factors of OSCC, as well as to establish a multivariate survival prediction model.

\section{Materials and methods}

Patients. We performed an observational study on a cohort of 68 patients diagnosed with OSCC who were surgically treated 
at the Maxillofacial Surgical Unit of the Santiago Teaching Hospital (Hospital Clinico Universitario de Santiago), Galicia, Spain, between January 2001 and March 2010. The inclusion criteria was established according to the surgical treatment in compliance with standard procedures, including resection of the primary tumor; radical, selective ipsilateral or bilateral removal of the regional lymph glands; clinical and pathological data and the availability of sufficient paraffin-embedded material to construct matrices. The clinical and pathological variables of each case included age, gender, tumor location, tumor stage, smoking habits, drinking habits, recurrence, dysplasia in the adjacent margin and vital status (death, by any cause) until February 2011.

The sample consisted of 35 men (51.5\%) and 33 women (48.5\%), with an age range from 41 to 96 years (average age, $67 \pm 13.08$ years). Tumors were classified according to tumor stage at the time of diagnosis in accordance with the 7th Edition of the AJCC Cancer Staging Manual by the American Joint Committee on Cancer (19). Informed consent for use of the samples and data analysis were obtained from each patient or caretaker.

Tissue microarray generation. Hematoxylin and eosin-stained (H\&E) slides were available for review in all cases. Paraffin blocks were selected on the basis of the availability of suitable formalin-fixed, paraffin-embedded tissue (at least 1-mm thick). For characterization of immunohistochemical protein expression, we constructed five different tissue arrays containing representative areas of every tumor. After microscopic evaluation, two areas of each tumor were selected, avoiding necrosis and keratin pools. Each tissue array was assembled as previously described (20). Briefly, two 1.5-mm-diameter cylinders of tissue were obtained from representative areas of each archival paraffin block and arrayed into a new recipient paraffin block with a custom-built precision instrument (Beecher Instruments, Silver Spring, MD, USA). These tissues were fixed in $4 \%$ buffered formalin and were paraffin-embedded according to routine procedures. Areas chosen for the cylinder core were representative of the tumors. In addition, normal tonsil samples were placed adjacent to the tumoral tissues to serve as internal controls and to ensure the quality of staining in the slides. Initial sections were stained with hematoxylin and eosin to verify histopathologic findings.

Immunohistochemistry. Tissue sections $(3-\mu \mathrm{m})$ from the TMA blocks were sectioned and applied to special immunohistochemistry coated slides (Dako, Glostrup, Denmark). Immunohistochemical analysis for c-myc was performed using a monoclonal antibody (clone 9E11; Novocastra, Newcastle, UK) with a concentration 1:100, according to the manufacturer's instructions. In brief, antigen retrieval was performed for $10 \mathrm{~min}$ at $95-99^{\circ} \mathrm{C}$ in a water bath, with a citrate buffer, $\mathrm{pH}$ 9.0. After blocking endogenous peroxidase activity, the slides were incubated for $30 \mathrm{~min}$ with the c-myc antibody. A secondary antibody reagent (polymer-based goat anti-mouse antibody fragment conjugated to horseradish peroxidase) was applied for $30 \mathrm{~min}$. After applying the chromogenic visualization step using the 3,3'-diaminobenzidine chromogen, slides were counterstained with hematoxylin. Negative controls were performed using the negative reagent control (isotype control antibody). Dysplasia was graded as mild, moderate, severe and carcinoma 'in situ', according to the criteria of the WHO (21).

Evaluation of immunohistochemical results, image digitizing and semiquantitative analysis. Cases showing cytoplasmic or nuclear positivity for c-myc were considered as positive. Slides were digitized using an automated slide scanner to produce high-resolution images for visual quantitative analysis using an ACIS $^{\circledR}$ III automatic image analysis system (Dako). The digital images of the slides were captured by the ACIS scanner at low power magnification, and the entire slide images were viewed on a monitor. The regions with the highest immune percentage of positive cells were selected for further automatic scoring. A minimum of three of these areas containing only tumor cells was selected manually for quantitative evaluation. The final score was the average result of the different areas measured. To confirm the accuracy of the measurements, selected areas from 10 of the specimens were measured three times.

Statistical analysis. Qualitative variables are expressed as frequencies and percentages; quantitative variables are expressed as means (standard deviation) and ranges. The $\chi^{2}$ test or Fisher's exact test was used as required to compare the qualitative variables. ANOVA or the Kruskal-Wallis test was used to contrast quantitative and qualitative variables. An association was considered statistically significant when the P-value was $\leq 0.05$. The Kaplan-Meier method/estimator and the Cox regression model were used for evaluating survival in the study sample.

Initially, we carried out a univariate analysis in which we studied the Kaplan-Meier curves of each of the categorical/ qualitative variables to assess if we detected differences in the survival between the different groups or levels of these variables. Subsequently, we adjusted the Cox regression univariate models to assess the influence of each of the analyzed variables on the survival prognosis.

A time-dependent multivariate Cox regression mode was fitted to jointly evaluate the possible risk factors in terms of survival. The recurrence of the patients was considered as the time-dependent covariate. The predictive multivariate analysis/model was performed using a stepwise procedure in terms of the best (the lowest) Akaike Information Criterion (AIC) value. The magnitude of the association between covariates and survival was evaluated through hazard ratios (HR), together with their corresponding 95\% confidence intervals (CI). Taking censored survival times into account, the log hazard ratios of the Cox model were used as criterion variables $\mathrm{Y}$, to construct time-dependent ROC curves (22).

All statistical analyses were conducted using SPSS Statistics 17.0 and R 2.15.0 (R Development Core Team, 2012), using the survival package (for fitting parametric Cox regression models), the survivalROC package (for computing time-dependent ROC curves) and the censboot function (from the bootstrap package) for bootstrapping survival models with censored observations. The function stepAIC (from the MASS package) was also used for obtaining the multivariate model with the best AIC. All these packages are freely available at http://www.R-project.org. 
Table I. Clinical characteristics of the OSCC patients, c-myc expression and association of variables.

\begin{tabular}{|c|c|c|c|}
\hline Characteristics & $\begin{array}{c}\text { Patients } \\
\mathrm{n}(\%)\end{array}$ & $\begin{array}{c}\mathrm{N}=53 \\
\mathrm{c}-\mathrm{myc} \\
\text { mean }(\mathrm{SD})\end{array}$ & P-value \\
\hline \multicolumn{4}{|l|}{ Gender } \\
\hline Male & $35(51.5)$ & $44.40(25.56)$ & 0.092 \\
\hline Female & $33(48.5)$ & $56.47(25.58)$ & \\
\hline \multicolumn{4}{|l|}{ Exposure to tobacco } \\
\hline Non-smoker (never) & $32(47.1)$ & $56.15(5.00)$ & $\mathbf{0 . 0 5 ^ { \mathrm { a } }}$ \\
\hline Former smoker ( $>10$ years) & $24(35.3)$ & $52.43(5.98)$ & \\
\hline Current smoker ( $\geq 5$ years) & $12(17.6)$ & $32.69(7.47)$ & \\
\hline \multicolumn{4}{|l|}{ Exposure to alcohol } \\
\hline Non-drinker & $33(48.5)$ & $56.28(25.32)$ & 0.206 \\
\hline Not current drinker & $13(19.1)$ & $52.18(26.06)$ & \\
\hline Current drinker & $22(32.4)$ & $42.03(26.05)$ & \\
\hline \multicolumn{4}{|l|}{ Primary location } \\
\hline Buccal mucosa & $6(9)$ & $40.05(11.45)$ & 0.208 \\
\hline Gums & $17(25.4)$ & $40.99(26.53)$ & \\
\hline Retromolar trigone & $6(9)$ & $57.80(32.77)$ & \\
\hline Tongue & $22(32.8)$ & $57.13(24.58)$ & \\
\hline Floor of mouth & $8(11.9)$ & $39.77(24.46)$ & \\
\hline Soft palate & $8(11.9)$ & $65.53(25.38)$ & \\
\hline \multicolumn{4}{|l|}{$\mathrm{T}$} \\
\hline $\mathrm{T} 1$ & $21(30.9)$ & $56.00(24.26)$ & 0.286 \\
\hline $\mathrm{T} 2$ & $21(30.9)$ & $41.87(25.06)$ & \\
\hline $\mathrm{T} 3$ & $4(5.9)$ & $68.27(11.00)$ & \\
\hline $\mathrm{T} 4$ & $22(32.4)$ & $50.11(28.66)$ & \\
\hline \multicolumn{4}{|l|}{$\mathrm{N}$} \\
\hline NO & $55(80.9)$ & $49.22(27.21)$ & 0.462 \\
\hline N1 & $7(10.3)$ & $65.98(12.44)$ & \\
\hline $\mathrm{N} 2$ & $6(8.8)$ & $47.52(21.80)$ & \\
\hline \multicolumn{4}{|l|}{ Clinical stage } \\
\hline I & $20(29.4)$ & $56.01(24.26)$ & 0.450 \\
\hline II & $12(17.6)$ & $42.06(27.70)$ & \\
\hline III & $9(13.2)$ & $60.94(20.13)$ & \\
\hline IV & $27(39.7)$ & $47.65(27.54)$ & \\
\hline \multicolumn{4}{|l|}{ Differentiation } \\
\hline Good & $30(44.1)$ & $51.06(5.49)$ & 0.970 \\
\hline Moderate & $30(44.1)$ & $49.55(5.24)$ & \\
\hline Poor & $8(11.8)$ & $50.45(13.09)$ & \\
\hline \multicolumn{4}{|l|}{ Recurrence } \\
\hline Yes & $29(42.6)$ & $50.39(25.87)$ & 0.979 \\
\hline No & $39(57.4)$ & $50.19(1.56)$ & \\
\hline \multicolumn{4}{|l|}{ Dysplasia in margin } \\
\hline No & $38(55.9)$ & $51.46(1.29)$ & 0.822 \\
\hline Low & $8(11.8)$ & $40.55(2.94)$ & \\
\hline Moderate & $4(5.9)$ & $49.35(20.29)$ & \\
\hline Severe & $1(1.5)$ & 68.64 & \\
\hline Carcinoma in situ (CIS) & $17(25)$ & $51.91(27.91)$ & \\
\hline
\end{tabular}

a Statistically significant.

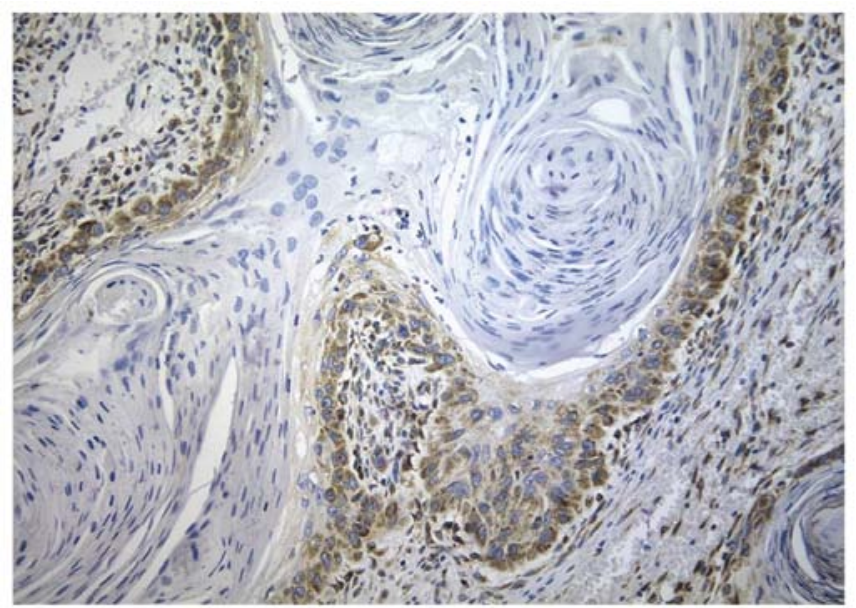

Figure 1. A case of oral squamous cell carcinoma showing moderate cytoplasmic staining while nuclei are only faintly positive. In this case, expression of the antibody was restricted to the lower layers of the tumor nests.

\section{Results}

Clinical, anatomical and pathological characteristics of the sample. The main clinical characteristics of the 68 patients selected for the present study are documented in Table I. Tumors were classified into initial stage (stages I and II), which accounted for 32 cases (47.8\%), and advanced stage (stages III and IV), which amounted to 36 cases (52.9\%). More men were diagnosed in early tumor stages [21 (65.6\%)], whereas women were found more frequently in advanced stages at the time of initial diagnosis $[22(61.1 \%)]\left(\chi^{2}=4.848, \mathrm{P}<0.05\right)$.

In terms of the relationship with exposure to tobacco, no statistically significant differences in terms of staging at the time of diagnosis $\left(\chi^{2}=1.227, \mathrm{P}=0.541\right)$ were noted. In regards to alcohol, of the 22 cases exposed to the carcinogen, $16(72.7 \%)$ were diagnosed in early stages $\left(\chi^{2}=11.338, \mathrm{P}<0.01\right)$.

The existence of dysplasia in the adjacent margin was positive in $42.6 \%$ of cases; $34.4 \%$ of the tumors in initial stages and $50 \%$ of the tumors in advanced stages $\left(\chi^{2}=2.176\right.$, $\mathrm{P}=0.337)$. The existence of CIS was slightly higher in advanced stage tumors [9 (25\%)] in contrast to $21.9 \%$ found in initial cases, although the differences were not statistically significant.

c-myc expression in OSCC. Immunohistochemistry showed both nuclear and cytoplasmic staining in neoplastic cells, while in many cases, the intensity was higher in the cytoplasm than that in the nuclei (Fig. 1).

The average expression of c-myc $(\mathrm{N}=53)$ was 50.32 (SD, 26.05) with a range from 6.60 to 99.48 ; similar for the initial stages [mean 50.77 (25.94)] and advanced stages [49.94 (26.59)] $(\mathrm{F}=0.013 ; \mathrm{P}=0.909)$. Women showed higher levels [56.47 (25.58)] than men [44.40 (25.56)] although there were no statistically significant differences $(\mathrm{F}=2.951 ; \mathrm{P}=0.877)$. The patients showed virtually similar values of c-myc in terms of the degree of tumor differentiation (Kruskal-Wallis $\chi^{2}=0.062$; $\mathrm{P}=0.970$ ). Non-smoking patients had higher levels of c-myc [56.15 (5.00)], showing statistically significant differences (Kruskal-Wallis $\chi^{2}=5.975 ; \mathrm{P}=0.05$ ). We found no statistically significant relationship between the quantitative expression 
A

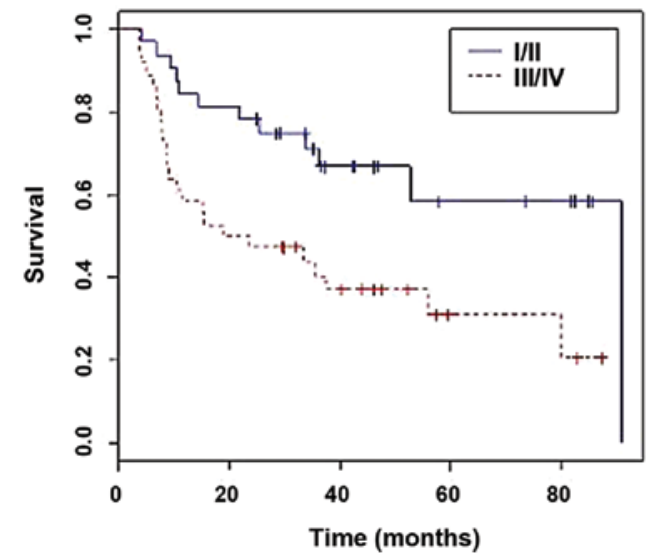

B

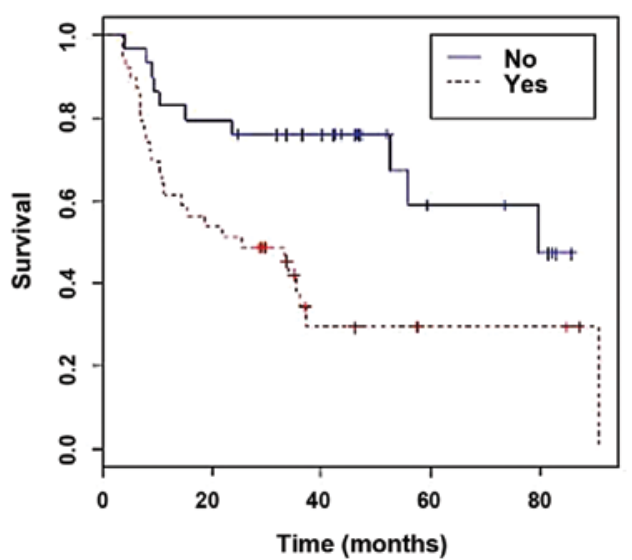

Figure 2. Kaplan-Meier survival curves. (A) The patients at initial stages exhibited prolonged survival (40.72 months) when compared with the patients in advanced stages (28.6 months). (B) The survival of the recurrence group (Yes) was reduced when compared with the survival of the non-recurrence group (No).

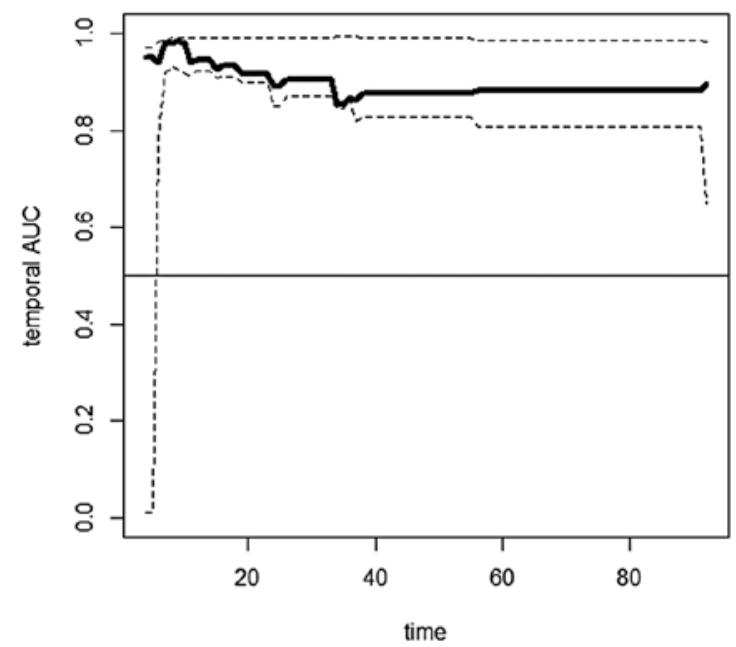

Figure 3. Temporary AUC shows an approximate mean value of 0.9 for the follow-up between 35 months and the end of the follow-up period, which indicates a good discrimination capacity of the Cox model.

of c-myc and any other clinical or pathological parameters (Table I).

Survival and follow-up analysis. The average follow-up was 33.5 months (CI, 28.23-40.38). Of the 36 (52.9\%) patients who died, $24(66.7 \%)$ were in the advanced stage group at the time of diagnosis $\left(\chi^{2}=5.785, \mathrm{P}<0.05\right)$. The average survival of the sample was 50.52 months (95\% CI, 41.07-59.96); according to the Kaplan-Meier curve, the cases at the initial stages had a higher survival rate (40.72 months) than those in advanced stages (28.6 months) and the differences were statistically significant $(\mathrm{P}<0.01)$ (Fig. $2 \mathrm{~A})$. Recurrence occurred in 39 cases $(57.4 \%)$ during the follow-up period, regardless of the tumor stage at the time of diagnosis $\left(\chi^{2}=0.30, \mathrm{P}=1.000\right)$. We detected statistically significant differences in the survival of patients with recurrence in contrast with those who did not relapse, showing a lower overall survival rate in the recurrence group $(\mathrm{P}<0.01)$ (Fig. 2B). Survival was also statistically significantly reduced in patients with any degree of dysplasia in the adjacent margin, in contrast with those who did not have dysplasia $(\mathrm{P}<0.05)$.

The Cox univariate regression analysis verified that the effect of the value of c-myc alone was not statistically significant $(\mathrm{P}=0.735)$. In a multivariate Cox analysis, however, the multivariate with the lower ACI obtained included the covariates: recurrence, c-myc, gender, location, differentiation, stage, size, alcohol consumption, dysplasia in the adjacent margin, interaction between c-myc and recurrence, and the interaction between gender and stage (ACI=155.0655). All of the variables were statistically significant, except for gender, stage and dysplasia in the adjacent margin. Gender and stage were not significant, but their relevant interactions were (Table II). Using this model, we observed that patients with recurrence had a 8303.37-fold higher risk than those without recurrence $(\mathrm{P}<0.01$; HR, 8303.37; 95\% CI, 34.30-2010000). For each unit of increase of c-myc, the risk increased by $1.15(\mathrm{P}<0.001$; HR, $1.150 ; 95 \%$ CI, 1062-1245). Patients with tumors located in the gum presented a 278.86-fold higher risk $(\mathrm{P}<0.001$; HR, 278.86; 95\% CI, 13.76-5653), followed by tumors in the tongue, with a risk of $16.24(\mathrm{P}<0.05$; HR, 16.24; 95\% CI, 1.37-193) when compared to tumors located in the buccal mucosa. Patients with moderate differentiation presented a risk 8.87-fold higher ( $\mathrm{P}<0.01$; HR, 8.87; 95\% CI, 2.01-39.13) than those with welldifferentiated tumors. We found the same results for poorly differentiated tumors, which showed a risk 7.48-fold higher $(\mathrm{P}<0.05$; HR, 7.48; 95\% CI, 1.06-52.73). In patients who were former drinkers, the risk decreased by $0.02(\mathrm{P}<0.001 ; \mathrm{HR}$, 0.02; 95\% CI, 0.02-0.19).

Temporary AUC showed an approximate mean value of 0.9 for the follow-up between 35 months and the end of the followup period, which indicates a good discrimination capacity of the Cox model (Fig. 3).

\section{Discussion}

The influence of c-myc in the carcinogenic process, in general, has been previously described in many tumors. In the specific case of oral tumors, Goessel et al (23) developed a cellular model of oral-esophageal carginogenesis, in which cyclin D1 
Table II. Final multivariate time-dependent Cox model including the studied variables.

\begin{tabular}{|c|c|c|c|}
\hline Variables & HR & $95 \% \mathrm{CI}$ & $\mathrm{P}$-value \\
\hline \multicolumn{4}{|l|}{ Recurrence } \\
\hline No & 1 & & \\
\hline Yes & 8303.372 & $34.30-2010000$ & $<0.01^{\mathrm{b}}$ \\
\hline c-myc & 1.150 & $1.062-1.245$ & $<0.001^{\mathrm{c}}$ \\
\hline \multicolumn{4}{|l|}{ Gender } \\
\hline Male & 1 & & \\
\hline Female & 0.4011 & $0.4416-3.643$ & $<0.01^{\mathrm{b}}$ \\
\hline \multicolumn{4}{|l|}{ Alcohol } \\
\hline No & 1 & & \\
\hline Currently & 1.90617 & $0.3871-9.386$ & 0.428 \\
\hline Not currently & 0.02146 & $0.024-0.1927$ & $<0.001^{\mathrm{c}}$ \\
\hline \multicolumn{4}{|l|}{ Tumor location } \\
\hline Buccal mucosa & 1 & & \\
\hline Gums & 278.8612 & $13.76-5653$ & $<0.001^{\mathrm{c}}$ \\
\hline Trigone & 1.3314 & $0.0581-30.51$ & 0.858 \\
\hline Tongue & 16.2401 & $1.367-193.0$ & $<0.05^{\mathrm{a}}$ \\
\hline Floor of mouth & 21.1731 & $0.5043-14.62$ & 0.103 \\
\hline Soft palate & 2.7970 & $0.1563-50.04$ & 0.485 \\
\hline \multicolumn{4}{|l|}{ Tumor size } \\
\hline $\mathrm{T} 1$ & 1 & & \\
\hline $\mathrm{T} 2$ & 27.517 & $1.865-406.1$ & $<0.05^{\mathrm{a}}$ \\
\hline T3 & 0.013 & $0.0002-0.6301$ & $<0.05^{\mathrm{a}}$ \\
\hline $\mathrm{T} 4$ & 0.027 & $0.0121-0.6142$ & $<0.05^{\mathrm{a}}$ \\
\hline \multicolumn{4}{|l|}{ Differentiation } \\
\hline Good & 1 & & \\
\hline Moderate & 8.8741 & $0.1563-50.04$ & $<0.01^{\mathrm{b}}$ \\
\hline Poor & 7.4756 & $1.060-52.73$ & $<0.05^{\mathrm{a}}$ \\
\hline \multicolumn{4}{|l|}{ Tumor stage } \\
\hline $\mathrm{I} / \mathrm{II}$ & 1 & & \\
\hline III/IV & 0.8587 & $0.5043-14.62$ & 0.916 \\
\hline \multicolumn{4}{|l|}{$\begin{array}{l}\text { Dysplasia in } \\
\text { adjacent margin }\end{array}$} \\
\hline Without dysplasia & 1 & & \\
\hline Dysplasia & 2.6953 & $0.6047-12.01$ & 0.194 \\
\hline CIS & 0.3277 & $0.0542-1.981$ & 0.224 \\
\hline \multicolumn{4}{|l|}{$\begin{array}{l}\text { c-myc and } \\
\text { recurrence }\end{array}$} \\
\hline No & 1 & & \\
\hline Yes & 0.89792 & $0.8377-2221$ & $<0.01^{\mathrm{b}}$ \\
\hline
\end{tabular}

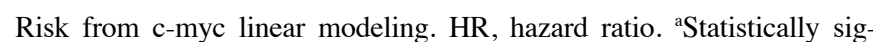
nificant at level 0.05 ; ${ }^{\mathrm{b}}$ statistically significant at level 0.01 ; ${ }^{\mathrm{c}}$ statistically significant at level 0.001. CIS, carcinoma in situ.

overexpression and inactivation of p53 lead to the immortalization of keratinocytes. Additionally, overexpression of ectopic epidermal growth factor receptor (EGFR) and c-myc, and the resulting malignant reactivation of telomerase induced by EGFR, are sufficient for the malignant transformation of oral epithelial cells. Thus, this demonstrated the importance of the overexpression of this gene in OSCC $(24,25)$.

Several studies have analyzed c-myc expression in this type of tumor showing different results, with an average positivity of $41.28 \%(2.4-75 \%)$ between the different studies (6,26-34). The results are extremely contradictory, as well as the variation in the quantification methods. In the present study we effectively developed a quantitative evaluation.

Shah et al (6) found a significantly higher expression in $\mathrm{T} 3 / \mathrm{T} 4$ tumors in comparison with T1/T2 tumors, although we were unable to verify this fact in our research. On the other hand, c-myc was correlated with tumor stage and lymphatic permeation, while in our study the expression was practically the same. Rodrigo et al (35) found no relationship between c-myc overexpression and tumor prognosis, similar to Hayry et al (33). Baral et al (27) found that tumors with positive p53 and c-myc were in the advanced stages of the disease (poorly differentiated, stage III), while OSCCs in early stages did not show positive immonoreactivity for p53 and c-myc.

Eversole and Sapp (36) studied c-myc levels in precancerous lesions and early cancerous lesions, and found that, in cases of dysplasia, in situ carcinoma and carcinoma, c-myc nuclear tinting was dominant in all the strata harboring atypical cells and the degree of tinting increased as the levels of atypia were higher. Shah et al (30) described an odds ratio (OR) of 6 in the transformation from hyperplasia to dysplasia, for c-myc (+) lesions and an OR of 3 for progressions beyond early stage carcinoma.

Vora et al (28), in a multivariate analysis, found that c-myc multiexpression is a clear indicator of poor prognosis, which can be used to evaluate specimens, paired with clinical staging, to determine locally advanced tumors. However, Tsuzuki et al (37), found no correlation between c-myc and 5-year survival of patients with oral and oropharangeal carcinomas. In our multivariate model, the increase in c-myc levels was positively statistically correlated with the risk of death.

The role of c-myc in carcinogenesis has been well described; however, its relationship with OSCC and clinical and pathological variables of tumors is not entirely clear. Thus, further study of this protein, which may have significant diagnostic, prognostic and therapeutic value is warranted. The determination of c-myc can be valuable when used together with other markers to assess the prognosis of OSCC patients.

\section{References}

1. Perez-Sayans M, Somoza-Martin JM, Barros-Angueira F, Reboiras-Lopez MD, Gandara Rey JM, Garcia-Garcia A: Genetic and molecular alterations associated with oral squamous cell cancer (Review). Oncol Rep 22: 1277-1282, 2009.

2. Choi S and Myers JN: Molecular pathogenesis of oral squamous cell carcinoma: implications for therapy. J Dent Res 87: 14-32, 2008.

3. Vairaktaris E, Spyridonidou S, Papakosta V, et al: The hamster model of sequential oral oncogenesis. Oral Oncol 44: 315-324, 2008.

4 Ginos MA, Page GP, Michalowicz BS, et al: Identification of a gene expression signature associated with recurrent disease in squamous cell carcinoma of the head and neck. Cancer Res 64: 55-63, 2004.

5. Perez-Sayans M, Pilar GD, Barros-Angueira F, SuarezPenaranda JM, et al: Current trends in miRNAs and their relationship with oral squamous cell carcinoma. J Oral Pathol Med 41: 433-443, 2012. 
6. Shah NG, Trivedi TI, Tankshali RA, et al: Prognostic significance of molecular markers in oral squamous cell carcinoma: a multivariate analysis. Head Neck 31: 1544-1556, 2009.

7. Gallant P and Steiger D: Myc's secret life without Max. Cell Cycle 8: 3848-3853, 2009.

8. Pelengaris S, Khan M and Evan G: c-MYC: more than just a matter of life and death. Nat Rev Cancer 2: 764-776, 2002.

9. Whyte DA, Broton CE and Shillitoe EJ: The unexplained survival of cells in oral cancer: what is the role of p53? J Oral Pathol Med 31: 125-133, 2002

10. Lebofsky R and Walter JC: New $M y c$-anisms for DNA replication and tumorigenesis? Cancer Cell 12: 102-103, 2007.

11. Spandidos DA, Yiagnisis M, Papadimitriou K and Field JK: ras, c-myc and c-erbB-2 oncoproteins in human breast cancer. Anticancer Res 9: 1385-1393, 1989.

12. Varley JM, Swallow JE, Brammar WJ, Whittaker JL and Walker RA: Alterations to either c-erbB-2(neu) or c-myc protooncogenes in breast carcinomas correlate with poor short-term prognosis. Oncogene 1: 423-430, 1987.

13. Riou GF: Proto-oncogenes and prognosis in early carcinoma of the uterine cervix. Cancer Surv 7: 441-456, 1988.

14. Field JK, Spandidos DA, Stell PM, Vaughan ED, Evan GI and Moore JP: Elevated expression of the c-myc oncoprotein correlates with poor prognosis in head and neck squamous cell carcinoma. Oncogene 4: 1463-1468, 1989.

15. Nakagawa M, Takizawa N, Narita M, Ichisaka T and Yamanaka S: Promotion of direct reprogramming by transformation-deficient Myc. Proc Natl Acad Sci USA 107: 14152-14157, 2010.

16. Adams JM, Kelly PN, Dakic A, Carotta S, Nutt SL and Strasser A: Role of 'cancer stem cells' and cell survival in tumor development and maintenance. Cold Spring Harb Symp Quant Biol 73: 451-459, 2008.

17. Eilers $M$ and Eisenman RN: Myc's broad reach. Genes Dev 22: 2755-2766, 2008.

18. Nair SK and Burley SK: Structural aspects of interactions within the Myc/Max/Mad network. Curr Top Microbiol Immunol 302: 123-143, 2006.

19. American Joint Committee on Cancer: Lip and oral cavity. In: Cancer Staging Manual. Edge SB, Fritz AG, Byrd DR, Greene FL, Trotti A III and Compton CC (eds). 7th edition Springer, New York, pp1-4, 2010.

20. Kononen J, Bubendorf L, Kallioniemi A, et al: Tissue microarrays for high-throughput molecular profiling of tumor specimens. Nat Med 4: 844-847, 1998.

21. World Health Organization Classification of Tumours: Head and Neck Tumors. In: Pathology and Genetics. Barnes L, Eveson JW, Reichart P and Sidransky D (eds). 9 edition. IARC Press, Lyon, pp177-180, 2005.

22. Heagerty PJ, Lumley T and Pepe MS: Time-dependent ROC curves for censored survival data and a diagnostic marker. Biometrics 56: 337-344, 2000.

23. Goessel G, Quante M, Hahn WC, et al: Creating oral squamous cancer cells: a cellular model of oral-esophageal carcinogenesis. Proc Natl Acad Sci USA 102: 15599-15604, 2005.
24. Foster KW, Ren S, Louro ID, et al: Oncogene expression cloning by retroviral transduction of adenovirus E1A-immortalized rat kidney RK3E cells: transformation of a host with epithelial features by c-MYC and the zinc finger protein GKLF. Cell Growth Differ 10: 423-434, 1999.

25. Perez-Sayans M, Suarez-Penaranda JM, Pilar GD, BarrosAngueira F, Gandara-Rey JM and Garcia-Garcia A: What real influence does the proto-oncogene c-myc have in OSCC behavior? Oral Oncol 47: 688-692, 2011.

26. Freier K, Bosch FX, Flechtenmacher C, et al: Distinct sitespecific oncoprotein overexpression in head and neck squamous cell carcinoma: a tissue microarray analysis. Anticancer Res 23: 3971-3977, 2003

27. Baral R, Patnaik S and Das BR: Co-overexpression of p53 and c-myc proteins linked with advanced stages of betel- and tobacco-related oral squamous cell carcinomas from eastern India. Eur J Oral Sci 106: 907-913, 1998.

28. Vora HH, Shah NG, Patel DD, Trivedi TI and Chikhlikar PR Prognostic significance of biomarkers in squamous cell carcinoma of the tongue: multivariate analysis. J Surg Oncol 82: 34-50, 2003.

29. Takes RP, Baatenburg de Jong RJ, Schuuring E, Litvinov SV, Hermans J and Van Krieken JH: Differences in expression of oncogenes and tumor suppressor genes in different sites of head and neck squamous cell. Anticancer Res 18: 4793-4800, 1998.

30. Shah NG, Trivedi TI, Tankshali RA, et al: Molecular alterations in oral carcinogenesis: significant risk predictors in malignant transformation and tumor progression. Int J Biol Markers 22: 132-143, 2007.

31. Martin-Ezquerra G, Salgado R, Toll A, et al: Multiple genetic copy number alterations in oral squamous cell carcinoma: study of $M Y C, T P 53, C C D N 1, E G F R$ and $E R B B 2$ status in primary and metastatic tumours. Br J Dermatol 163: 1028-1035, 2010.

32. Fujieda S, Inuzuka M, Tanaka N, et al: Expression of p27 is associated with Bax expression and spontaneous apoptosis in oral and oropharyngeal carcinoma. Int J Cancer 84: 315-320, 1999.

33. Hayry V, Makinen LK, Atula T, et al: Bmi-1 expression predicts prognosis in squamous cell carcinoma of the tongue. Br J Cancer 102: 892-897, 2010.

34. Takes RP, Baatenburg de Jong RJ, Wijffels K, et al: Expression of genetic markers in lymph node metastases compared with their primary tumours in head and neck cancer. J Pathol 194: 298-302, 2001.

35. Rodrigo JP, Lazo PS, Ramos S, Alvarez I and Suarez C: MYC amplification in squamous cell carcinomas of the head and neck. Arch Otolaryngol Head Neck Surg 122: 504-507, 1996.

36. Eversole LR and Sapp JP: c-myc oncoprotein expression in oral precancerous and early cancerous lesions. Eur J Cancer B Oral Oncol 29B: 131-135, 1993.

37. Tsuzuki H, Sunaga H, Ito T, Narita N, Sugimoto C and Fujieda S: Reliability of platelet-derived endothelial cell growth factor as a prognostic factor for oral and oropharyngeal carcinomas. Arch Otolaryngol Head Neck Surg 131: 1071-1078, 2005. 